\title{
Plans laid for new lobby
}

Canberra

AUSTRALIAN scientists and technologists have taken the first step towards the formation of their own national lobby group, to take its place alongside the others crowding the political landscape. Almost every other interest group seems to have a lobbying arm. But Australian scientists, although producing two per cent of the world's published scientific literature from a population base comprising less than onehalf of one per cent of the total, have only now realized that a performance-enhanced mousetrap, say, will not automatically be taken up by industry, or even recognized by the media, let alone by politicians. This is why, with a few notable exceptions, scientists are a fugitive breed in Australia, misunderstood when not actually invisible. Last week's nucleation at a meeting in the Australian Academy of Science of a body to lobby government and spread the good word generally may help to rectify the situation.

The spur has been the August 1984 federal budget, in which publicly supported science was cut back by five per cent. With recruiting among academics and in the Commonwealth Scientific and Industrial Research Organization (CSIRO) already at a standstill, it began to look as if even scientists holding permanent jobs would have their research hindered. An ad hoc group of eight scientific societies expressed disquiet about the cuts. The Academy of Science established a 16-member National Committee for the Promotion of Science and Technology under the chairmanship of Professor Max Bennett, a neurobiologist from the University of Sydney.

The immediate outcome was the $\mathrm{Na}$ tional Meeting of Concern on Science and Technology at which the elected leaders of 68 scientific and industrial societies and two academies representing about 80,000 members voted to elect an interim federation committee. That committee's first task is to explore the setting up of two secretariats, one of which will be a small professional lobbying group based in Canberra to facilitate communication between government and the scientific community, especially at budget time.

The other committee (probably based in Sydney), will provide a science and technology information service modelled on the Media Resource Service of the US Scientists Institute for Public Information. Through it, people in the news media, education and politics throughout Australia would be put in touch with experts for comment on scientific matters. The twelvemember interim committee, under the chairmanship of Professor Fred Smith, a physicist at Monash University, is due to report in six months.

A mood of optimism pervaded the meeting, but there were objections that

political consensus may be difficult to achieve between academic, CSIRO and industrial scientists, particularly because the specialist societies (some with their own lobbying apparatus) differ greatly in size.

The federal Minister for Industry, Technology and Commerce, Senator John Button, said that, although he welcomed the possibility of discussions with such widely representative groups, not all basic research could be convincingly sold as seed corn for the future. In the interests of industrial restructuring, he said, public financing "may not be just where you are used to it being".

The Minister for Science, Mr Barry Jones, was absent from Australia during the meeting, but in February this year

\section{Famine}

\section{Remedy not by bread alone}

Anaheim, California

THE more equitable distribution of available food supplies is not, by itself, the best way of avoiding famine. This is what a gathering of biologists was repeatedly told last week. And so it is a matter of urgency that biologists should pay more attention to the prediction, the causes of onset and the prevention of famine.

Organized by Dr Barry Bloom of the Albert Einstein College of Medicine, the symposium was belatedly and exceptionally tagged onto the 300 or so sessions already jamming the programme of this year's meeting in Anaheim of the Federation of American Societies for Experimental Biology (FASEB). Bloom, an immunologist with a special interest in leprosy, was prompted to organize the symposium by the present African famines. "We have learned so few lessons", he says, "that each new catastrophe tends to repeat some of the classic errors from the past."

One priority in research should be to develop criteria for predicting famines in time to prevent them. "In most circumstances, one is likely to have one group of people politically or emotionally interested in asserting that the situation is worse than it is and another arguing the opposite", says Bloom.

That theme was taken up by John Mellor of the International Food Policy Research Institute in Washington, DC, who argued that if more famine-prone countries had democratic governments and a free press, we might learn of problems in time to prevent them. Foreign aid must be channelled into transportation systems so that food ca be distributed, he said, and into the training of an elite of agricultural personnel. The priority for scientific research should be the mounting of a green revolution in Africa.

Although confident that scientists could () 1985 Nature Publishing Group something was salvaged from the 1984 budget wreck in the form of one of his favourite projects - the Commission for the Future.

The aim of the new body is also to raise public awareness and debate about science and technology, especially about the ways in which technological change will affect the lives of ordinary people, and the choices they must make in education and employment. The commission is headed by $\mathrm{Mr}$ Philip Adams, an advertising executive and all-round pundit, who is an old friend of Mr Jones.

The scene is set, then, for the emergence of science (and some scientists) from the shadows where they have languished politically for so long. Noting how badly the job of advocacy has been done in the past, Professor Smith says that, realistilly, a major impact may not be felt for five years.

Jeffrey Sellar

produce the means for such a revolution, Dr Robert Goldman, of the plant biotechnology company Calgene, wondered if it would be put into effect. The science that fuelled the green revolution that saved India and Mexico from famine was developed in the public sector and applied without profit. Now that the impetus for plant improvement has passed to the private sector, particularly agricultural biotechnology companies, the developing countries may be less able to win benefits.

Famine is, in any case, the end result of a chronic condition of malnutrition. Eight hundred million people worldwide are calory-deficient, and "it seems likely that whole societies have been forced to adapt to this", says Dr Neville Scrimshaw of the Massachusetts Institute of Technology. Adaptation means reducing physical activity, which can have severe social consequences. Less obvious deficiences of iron, vitamin $\mathbf{A}$ and iodine are widespread, debilitating and make people more prone to infections which, in turn, can exacerbate malnutrition.

The downward spiral that ends in famine is best broken by immunology, in the opinion of Stephen Joseph of UNICEF. Calling for more research into both vaccine development and the inter-relationship between immunity, nutrition, infection and growth, he said that scientific research must go hand in hand with improved management of preventive programmes and better education of those who should benefit.

After the symposium, Dr Bloom complained that no more than 200 people had attended. Up to 15,000 people were expected to register for FASEB, and although the famine symposium was held the evening before the full meeting got under way, 2,000 people turned up next day at a lecture on the molecules involved in lymphocyte activation. Peter Newmark 